DOI: 10.12731/2070-7568-2019-2-7-21

УДК 332

\title{
УПРАВЛЕНИЕ РИСКАМИ \\ КАК ИНСТРУМЕНТ РАЗВИТИЯ ТРАНСПОРТНОЙ ОТРАСЛИ В РОССИИ
}

\section{Бычкова А.А., Никулина Н.Л.}

В статье представлены теоретические аспекты управления рисками. Отражены результаты деятельности железнодорожного транспорта за 2015-2017 г2. по направлениям перевозки пассажиров и грузов в России. Проанализирована степень разработанности методов и механизмов управления рисками в отечественных и зарубежных источниках.

Цель исследования: развитие теоретических положений, разработка рекомендаций для улучшения методов и механизмов рискменеджмента транспортной отрасли.

Методы и методология: методы эмпирического, теоретического исследования, экономического и сравнительного анализа, данные статистики, анализ научных исследований, группировка.

Результатом анализа стала разработка ряда рекомендаций $и$ мероприятий по снижению, предотвращению рисков предприятий транспортной отрасли.

Область применения результатов. Результаты анализа могут быть использованы для формирования Стратегии пространственного развития железнодорожного транспорта Российской Федерачии на период до 2025 года.

Ключевые слова: транспортная отрасль; железнодорожный транспорт; риск; риск-менеджмент; методы идентификации рисков; мероприятия по снижению и предотвращению рисков. 


\title{
RISK MANAGEMENT \\ AS A TOOL FOR THE DEVELOPMENT \\ OF THE TRANSPORT INDUSTRY IN RUSSIA
}

\author{
Bychkova A.A., Nikulina N.L.
}

The article presents the theoretical aspects of risk management, reflects the results of rail transport activities for 2015-2017 in the direction of transport of passengers and cargo in Russia. The degree of development of risk management methods and mechanisms in domestic and foreign sources has been analyzed.

The purpose of the study: the development of theoretical provisions, the development of recommendations to improve the methods and mechanisms of risk management of the transport industry.

Methods and methodology: methods of empirical, theoretical research, economic and comparative analysis, analysis of scientific research, statistics, grouping.

Results. The analysis resulted in the development of a number of recommendations and measures to reduce and prevent the risks of the enterprise of the transport industry.

Practical implications. The results of the analysis can be used for the spatial development strategy of the Russian Federation for the period up to 2025.

Keywords: transport industry; rail transport; risk; risk management; methods of risk identification; measures to reduce and prevent risks.

\section{Введение}

В настоящее время предприятия развиваются в сложной, постоянно меняющейся социальной, политической и экономической обстановке. Организации вынуждены учитывать риски быстрой потери конкурентоспособности на рынке и финансовой устойчивости предприятия. Развитие научно-технических процессов, внедрение новейших информационных технологий, усложнение видов услуг, всемирная глобализация, доступ к финансовым ресурсам актуали- 
зируют необходимость поиска новых методов и механизмов управления рисками на предприятии [5].

Риск-менеджмент - составная часть системы управления любой отрасли, направленная на получение доходов и сокращение убытков. Система управления должна учитываться в политике предприятия, бизнес-планах, текущей деятельности. Исследования зарубежной практики показывают, что система риск-менеджмента позволяет успешно управлять рисками, контролировать и смягчать убытки [15]. Управление рисками давно признано в зарубежных странах, в России это направление только начинает развиваться, компании осознают необходимость риск-менеджмента в управлении организацией. Актуальность темы обусловлена необходимостью совершенствования и развития методов и механизмов риск-менеджмента на предприятии для успешного развития в условиях рыночной экономики.

Новизна исследования состоит в совершенствовании способов снижения угроз транспортной компании на основе интегрированного управления рисками.

Основными задачи анализа являются: изучение и анализ причин возникновения и экономической сущности риска, определение особенностей управления рисками предприятия, формирование и разработка основных направлений совершенствования системы снижения рисков.

Резкое возрастание степени рисков заставило менеджеров компаний в различных отраслях экономики больше внимания уделять управлению рисками, использовать для оценки функционирования железнодорожной сети весь спектр рисков как с экономической стороны, так и со стороны политической, технической, законодательной.

\section{Материалы и методы исследования}

Степень разработанности проблемы. Исследователями в области управления рисками накоплен значительный теоретический, статистический и методический материал. Вопросам анализа и оценки рисков, методов и механизмов риск-менеджмента в конкретных 
отраслях посвящены труды многих ученых. Значительный вклад в развитие темы рисков внесли такие зарубежные экономисты, как: Дж.М. Кейнс, А. Маршалл, О. Моргенштейн, Ф. Найт, Дж. Нейман, И.С. Уильяме, Дж. Бароне-Адези, Т. Боллерслев, К. Гианнопоулос и др. [11].

Проблемой анализа и оценки риска посвящены труды и российских ученых, таких как: В.А. Абчук, А.П. Альгин, И. Аминов, К.М. Аргинбаев, М.И. Баканов, И.Т. Балабанов, Б.А. Райзберг, В.Т. Севрук, А.А. Спивак, В.Е. Кузнецов, М.А. Рогов, В.А. Чернов, Г.В. Чернова и др. [8].

Однако анализ работ показывает, что, несмотря на значительное количество исследований, остается множество вопросов, связанных с методами и механизмами управления рисками.

Для своевременного выявления и оценки рисков железной дороги можно рекомендовать использовать следующие методы:

1. Методы сбора и анализа экспертных оценок.

2. Анализ макроэкономических, международных и отраслевых прогнозов.

3. Статистический анализ данных.

4. Сценарное моделирование.

5. Экстраполяция.

6. Финансовая математика.

7. Теория вероятностей [9].

В настоящее время не существует единого мнения об экономической сущности риска, нет единой классификации, системы, недостаточно внимания уделено механизмам управления рисками. Существуют нерешенные методические и практические вопросы, нет обобщенной методологической системы управления рисками.

\section{Результаты исследования}

В современном мире сложная политическая, экономическая, постоянно меняющаяся социальная обстановка вносит свои коррективы в развитие предприятий. Происходит всемирная глобализация общества, несущая как положительное, так и отрицательное вли- 
яние на развитие экономики в целом, на деятельность конкретных предприятий [12]. В сложившейся ситуации наибольшее значение уделяется проблеме адаптации предприятий транспортной сферы к современным условиям, в том числе и к всевозможным угрозам [4].

Проблема адаптации к рискам возникает из-за специфики компаний. Каждая сфера деятельности отрасли по-своему уникальна и имеет свои недостатки и преимущества [7]. На примере транспортной отрасли можно рассмотреть систему управлениями и адаптации к угрозам. В таблице 1 представлены результаты анализа динамики деятельности транспортной отрасли.

Таблицуа 1. Динамика изменения пассажирооборота и грузооборота транспортной отрасли

\begin{tabular}{|c|c|c|c|c|c|c|}
\hline \multirow{2}{*}{ Вид транспорта } & $\mathbf{2 0 1 5}$ & $\mathbf{2 0 1 6}$ & $\mathbf{2 0 1 7}$ & $\begin{array}{c}\text { Изменение } \\
\text { к 2016 году }\end{array}$ & $\begin{array}{c}\text { Изменение } \\
\text { к 2017 году }\end{array}$ \\
\hline \multicolumn{7}{|c|}{ Пассажирооборот, млрд пассажиро-км } \\
\hline железнодорожный & 120,6 & 124,6 & 123 & 4 & $-1,6$ \\
\hline автобусный & 126,3 & 124,3 & 123,4 & -2 & $-0,9$ \\
\hline легковое такси & 0,3 & 0,4 & 0,5 & 0,1 & 0,1 \\
\hline трамвайный & 4,8 & 4,6 & 4,3 & $-0,2$ & $-0,3$ \\
\hline троллейбусным & 6 & 5,5 & 5,2 & $-0,5$ & $-0,3$ \\
\hline метрополитенный & 44,6 & 44,1 & 44,1 & $-0,5$ & 0 \\
\hline \multicolumn{2}{|c|}{0,06} & 0,09 & 0,1 & 0,03 & 0 \\
\hline внотреной & 0,5 & 0,6 & 0,6 & 0,1 & $-0,038$ \\
\hline воздушный водный & 226,8 & 215,6 & 258,8 & $-11,2$ & 43,24 \\
\hline Всего & $\mathbf{5 3 0}$ & $\mathbf{5 1 9 , 8}$ & $\mathbf{5 6 1}$ & $\mathbf{- 1 0 , 2}$ & $\mathbf{4 0 , 9}$ \\
\hline \multicolumn{7}{|c|}{ Грузооборот, млрд т-км } \\
\hline железнодорожный & 2306 & 2344 & 2493 & 38 & 149 \\
\hline автомобильный & 232 & 248 & 253 & 16 & 5 \\
\hline трубопроводный & 2444 & 2489 & 2615 & 45 & 126 \\
\hline \multicolumn{2}{|c|}{42} & 43 & 46 & 1 & 3 \\
\hline внутренний водный & 64 & 67 & 67 & 3 & 0 \\
\hline воздушный & 5,4 & 6,6 & 7,6 & 1 & 1 \\
\hline Транспорт всего & $\mathbf{5 0 9 3}$ & $\mathbf{5 1 9 8}$ & $\mathbf{5 4 8 2}$ & $\mathbf{1 0 5}$ & $\mathbf{2 8 4}$ \\
\hline
\end{tabular}

К одной из компаний транспортной отрасли относится ОАО «Российские железные дороги» [2] с колоссальными объемами грузовых и пассажирских перевозок на территории Российской Федерации и 
за ее пределами. Железная дорога имеет высокое значения для страны, поскольку относится к одному из основных видов транспорта, соединяющих в единое целое территорию государства, обеспечивая потребности населения различных регионов в пассажирообороте и грузообороте.

В структуре межвидовой конкуренции железная дорога по пассажирообороту за 2017 год занимает третье по значимости место, уступая воздушному и автобусному транспорту, по грузообороту железнодорожный транспорт находится на втором месте после трубопроводного [3]. Причиной отставания от первой позиции и снижения показателей могут являться риски. Идентификация рисков, а также нахождение мер предотвращения развития неблагоприятных ситуаций позволит улучшить функционирование транспортной компании и избежать высоких издержек, которые влияют на всю структуру транспортной отрасли.

С целью распознавания рисков можно применять классические методы, такие как опрос, анкетирование ключевых сотрудников и менеджеров фирмы, бенчмаркинг угроз [8, с. 104]. К главной задаче каждой из методик относится распознание негативных событий, которые могут отрицательно повлиять на деятельность компании. При исследовании и сборе информации использовались данные российской статистики за 2015-2017 гг., годовая отчетность ОАО «РЖД», итоги опроса экспертов (внутри организации и внешние) в области рисков. Первыми результатами анализа, представленными в лице компании РЖД, стали коэффициенты финансового положения предприятия [13].

Полученные результаты характеризуют железнодорожный транспорт как предприятие с достаточно «хорошим» уровнем платежеспособности, способное удовлетворять текущие обязательства, но при этом вероятность банкротства с высоким уровнем риска «красная зона». Основные возможные причины несоответствия итогов прогнозирования банкротства вызваны тем, что такой анализ не охватывает внешние факторы риска, свойственные российским условиям, а именно нестабильность экономической и финансовой обстановки в стране. 
Таблицуа 2.

Анализ финансового состояния ОАО «РЖД»

\begin{tabular}{|c|c|}
\hline Наименование показателя / описание & $\begin{array}{c}\text { Результат, } \\
\text { уд. ед. }\end{array}$ \\
\hline $\begin{array}{l}\text { Коэффициент текущей ликвидности - отражает способность пред- } \\
\text { приятия погашать свои обязательства сроком до } 1 \text { года. Норматив- } \\
\text { ное значение показателя находиться в пределах от } 0,5 \text { до } 0,8 \text { уд. ед. }\end{array}$ & 1,16 \\
\hline $\begin{array}{l}\text { Коэффициент быстрой ликвидности - применяется для выявле- } \\
\text { ния финансовых обязательств, которые можно оплатить за сред- } \\
\text { ства компании. Нормой считает результат от } 0,8 \text { до } 1 \text { уд. ед. }\end{array}$ & 0,84 \\
\hline $\begin{array}{l}\text { Коэффициент абсолютной ликвидности - показывает долю кра- } \\
\text { ткосрочных заемных средств, которые можно немедленно удовлет- } \\
\text { ворить при первостепенной необходимости. Для российских ком- } \\
\text { паний нормативное значение показателя от } 0,15 \text { до } 0,20 \text { уд. ед. }\end{array}$ & 0,19 \\
\hline $\begin{array}{l}\text { Коэффициент совокупной ликвидности - определяет общее со- } \\
\text { стояние фирмы на готовность оплачивать своими средствами } \\
\text { необходимые платежи. Показатель отображает соотношение } \\
\text { объема денежных средств фирмы на одну единицу текущих обя- } \\
\text { зательств, благоприятной ситуацией считается, когда текущие } \\
\text { активы выше текущие обязательства }[10, \text { с. } 210] .\end{array}$ & 0,30 \\
\hline $\begin{array}{l}\text { Пятифакторная модифицированная модель Альтмана определе- } \\
\text { ния вероятности банкротства. Если: } Z>2,9 \text { - зона финансовой } \\
\text { устойчивости «зеленая», } 1,8<Z<2,9 \text { - зона неопределенности } \\
\text { «желтая», } Z<1,8 \text { - зона финансового риска «красная» [10]. }\end{array}$ & 0,51 \\
\hline
\end{tabular}

Одним из неотъемлемых этапов управления неблагоприятными ситуациями является идентификация рисков. К основной информации для данного анализа относится: устав компании, внутренние распорядительные документы, финансовая отчетность, информация о состоянии рынка в настоящий момент, экономические и другие источники. В результате проведения исследования группой экспертов выявлены значимые угрозы для российской железной дороги - ситуации, действия которых способны повлиять на нормальное функционирование организации и могут привести к не достижению основных целей.

Наибольшее влияние на основные показатели деятельности компании могут оказать следующие риски:

- ухудшение макроэкономической ситуации в стране относительно прогнозов, заложенных в долгосрочную программу развития ОАО «РЖД»; 
- недостаточная индексация тарифов при опережающем изменении цен конкурентов на аналогичные услуги пассажиро- и грузоперевозок;

- слабо мотивированные программы поддержки потребителей в последствии приводят к снижению пассажиропотока, а снижение платежеспособности клиентов ведет к потере основного источника получения прибыли;

- отсутствие модернизации, ремонта существующего подвижного состава приводит к снижению эффективного использования транспортной сети;

- резкое изменение валютного курса приводит к недополучению прибыли, а также компания может понести потери от больших объемов грузоперевозок по валютному договору;

- нарушение сроков погрузки, отправки грузов ведет к потере клиентов.

Для предотвращения и своевременного реагирования на риски ОАО «РЖД» постоянно взаимодействует с основными потребителями услуг и подрядчиками, информируя их о потенциальных негативных последствиях принимаемых решений. Для снижения возможных последствий рисков железнодорожный транспорт повышает клиентоориентированность и качество предоставляемых услуг, а также реализует программу повышения эффективности работы.

\section{Обсуждение}

Размах процесса риск-менеджмента зависит от значимости управляющих решений, которые должны быть приняты в ходе предпринимательской деятельности. Практическое применение системы предотвращения рисков в ОАО «РЖД» призвано обеспечить защиту от угроз, нарушающих:

- условия сохранности жизни и здоровья пассажиров,

- сохранность грузоперевозок и багажа,

- экологическая безопасность,

- санитарная и пожарная безопасность. 
Обеспечение сохранности железной дороги от воздействия угроз при помощи системы предупреждения и предотвращения правонарушений, преступлений, недопущение ущерба для основных потребителей услуг компании. Железнодорожный транспорт подвержен внешним и внутренним угрозам, для анализа угроз отрасли целесообразно концентрировать внимание на внешних рисках, так как степень влияния их в разы выше и контроль таких неблагоприятных ситуаций сложнее, чем внутренних. Для целостного представления всех угроз существует группировка, характеризующая направленность воздействия.

Общзая классификация рисков:

политические - риски, предопределенные переменой общественно-политической ситуацией, оказывающие большое влияние на предпринимательскую деятельность (закрытие границ, запрет на экспорт товаров, боевые действия на территории государства);

экологические - риски обусловлены нарушениями определенных общепризнанных норм, нормативов по охране природной среды и безопасности жизнедеятельности;

социальные - риски связаны с неэффективной организацией социальной инфраструктуры, минусами в обеспечении защищенности работы сотрудников;

финансовые - возможность появления неблагоприятных финансовых результатов в виде утраты дохода или капитала при неопределённых обстоятельствах реализации предпринимательской деятельности;

кадровые - риски связаны с недостатком или избытком сотрудников у экономического субъекта, риски сопряжены с несоответствием характеристик фактически существующего в компании персонала с теми условиями, которые предприятие определяет с целью поиска собственных сотрудников [6];

профессиональные - возможность нанесения ущерба самочувствию персонала, сопряженная с небезопасными производственными условиями в трудовой период, при условии, что сотрудник имеет трудовой договор;

и многие другие риски [1]. 
Главными причинами риска аварий и катастроф на железнодорожном транспорте являются неисправности пути, подвижного состава, средств сигнализации, централизации и блокировки, ошибки диспетчеров, невнимательность и халатность машинистов.

Наиболее часто аварийные ситуации на железной дороге происходят с подвижным составом, такие как, сход, столкновения, наезды на препятствия на переездах, пожары и взрывы непосредственно в вагонах.

К отличительным особенностям рисковых ситуаций в системе управления транспортом относятся:

- удаленность места катастрофы от крупных населенных пунктов усложняет сбор достоверной информации в первый период и объем оказания первой медицинской помощи пострадавшим, труднодоступность подъездов к месту катастрофы и затрудненность применения инженерной техники;

- ликвидация пожаров (взрывов) на территории железнодорожных станций и узлов, связанная с необходимостью вывода железнодорожного состава с территории станции на перегоны;

- наличие случаев сложной медицинской обстановки, характеризующейся массовыми возникновениями травм различной степени тяжести, необходимость транспортировки большого количества пострадавших в другие города в связи со спецификой лечения;

- сложность в определении количества пассажиров, выехавших из различных мест и оказавшихся в зоне аварии, координация поиска выживших, а также розыск вещественных доказательств путем организации специализированных поисковых отрядов и прочесывания местности и т. д.

Наиболее эффективным способом разработки организационно-экономических механизмов ликвидации последствий аварий на транспортных коммуникациях является применение методологии риск-менеджмента и меры допустимого риска [11]. При этом должны учитываться особенности и экономические факторы транспортных катастроф. 


\section{Заключение}

Угрозы, которые компания идентифицирует, нуждаются в идентификации, чтобы предпринять действия для минимизации будущих потерь. Если риски не удается полностью ликвидировать, то именно методы снижения и лимитирования позволят модифицировать риск таким образом, что он изменит свою опасную зону на умеренную, допустимую. При выборе мер эксперты учитывают вероятность того, что рост идентифицированных угроз будет не соответствовать ожиданиям и превышать прогнозируемый уровень. Защитные факторы, разработанные для выявленных рисков, могут применяться для нескольких угроз. К примеру, выстраивание долгосрочных отношений с клиентами позволит снизить риски, связанные с изменением тарифного плана и выявить потребности для улучшения качества обслуживания.

Для учета влияния рисков при принятии стратегических решений компании рекомендуется:

- при принятии стратегических решений обязательно утвердить порядок действий и учитывать все стратегические риски [14];

- выработать процедуру для качественного анализа и оценки рисков;

- создать реестр, шкалу рисков, располагая риски по уровням сложности и времени наступления для определения очередности действий по отношению к каждой угрозе;

- разработать программу контроля над выполнением поставленных задач, оценку эффективности проводимых мероприятий, а также систему поощрения на всех уровнях организации.

\section{Благодарность}

Статья подготовлена в соответствии с Планом НИР для Лаборатории моделирования пространственного развития территорий ФГБУН Института экономики УрО РАН на 2019 год.

\section{Список литературы}

1. Батова И.Б. Сущность и функции предпринимательских рисков // Международный студенческий научный вестник. 2015. №2. 
URL: https://eduherald.ru/ru/article/view?id=11976 (дата обращения: 30.07.2019).

2. Новые горизонты 2017 // Годовой отчет ОАО «Российские железные дороги». 2017. URL: https://ar2017.rzd.ru/ru (дата обращения: 07.08.2019).

3. Егоренко С.Н. Транспорт // Регионы России. Социально-экономические показатели. Москва, 2018. С. 848-869.

4. Жуков М.Ю., Глоба С.Б. Оценка социально-экономической перспективности предприятий северных регионов России // Наука Красноярья. 2018. Т.7. №2. С. 144-166.

5. Иванов О.Б. Глобальные риски и тенденции современного мира // ЭТАП: экономическая теория, анализ, практика. 2017. №1. С. 7-20.

6. Куликова Я.А., Бердикова А.Н., Кузнецов И.А. Проблемы внедрения конфликт-менеджмента в управлении трудовым коллективом организации // Наука Красноярья. 2019. Т.8. №1. С. 7-24.

7. Кунцман А.А. Специфика адаптации современных компаний к условиям цифровой экономики // Инновации. 2017. №9(227). С. 14-21.

8. Макарова В.А. Формирование системы риск-менеджмента на предприятии // Вестник Псковского государственного университета. Серия: Экономика. Право. Управление. 2014. №4. С. 98-108.

9. Матвеенко Ю.И. Современные подходы к изучению риска // Известия Тульского государственного университета. Гуманитарные науки. 2012. №1-1. С. 165-173.

10. Савицкая Г.В. Экономический анализ: учебник 14-е изд., испр. и доп. М.: ИНФРА-М, 2017. 649 с.

11. Agoraki, M.-E.K., Delis, M.D., Pasiouras, F. Regulations, competition and bank risk-taking in transition countries // Journal of Financial Stability. 2011. №7(1), pp. 38-48.

12. Best practices in CCP Risk Management 2017. URL: https://www. lch.com/sites/default/files/media/files/Best $\% 20$ Practices $\% 20$ in $\% 20$ CCP\%20Risk\%20Management_3.pdf?utm_source=Risk.Net\&utm medium $=$ Double $\% 20$ MPU\&utm_term $=$ CPM\&utm_content $=$ Risk $\% 20$ Whitepaper\&utm_campaign=Risk $\% 20$ Whitepaper (дата обращения: 18.07.2019). 
13. Peter F. Elements of financial risk management 2nd ed. 2012, pp. 291-326.

14. Thomas S., Carl P. Management: function and strategy // Annotated instructor's edition 2nd ed., Indiana University, 2002. 662 p.

15. Thomsen S., Pedersen T. Ownership structure and economic performance in the largest European companies // Strategic Management Journal. 2000. №21(6), pp. 689-705.

\section{References}

1. Batova I.B. Sushchnost' i funktsii predprinimatel'skikh riskov [Classification of risk and reasons of their emergence]. Mezhdunarodnyy studencheskiy nauchnyy vestnik [International Student Science herald], 2015, no. 2. https://eduherald.ru/ru/article/view?id=11976

2. Novye gorizonty 2017 [New Horizons], Godovoy otchet OAO «Rossiyskie zheleznye dorogi», 2017 [Annual report JSCo Russian Railways]. https://ar2017.rzd.ru/ru

3. Egorenko S.N. Transport [Transport], Regiony Rossii. Sotsial'no-ekonomicheskie pokazateli [Regions of Russia. Social and economic indicators]. Moskva, 2018, pp. 848-869.

4. Zhukov M.Yu., Globa S.B. Otsenka sotsial'no-ekonomicheskoy perspektivnosti predpriyatiy severnykh regionov Rossii [Assessment of socio-economic prospects of enterprises in the northern regions of Russia]. Siberian Journal of Economics and Management, 2018, Vol. 7, no. 2, pp. 144-166.

5. Ivanov O.B. Global'nye riski i tendentsii sovremennogo mira [Global risk and trends of the modern world]. ETAP: ekonomicheskaya teoriya, analiz, praktika [Stage: economic theory, analysis, practice], 2017, no. 1, pp. 7-20.

6. Kulikova Ya.A., Berdikova A.N., Kuznetsov I.A. Problemy vnedreniya konflikt-menedzhmenta $\mathrm{v}$ upravlenii trudovym kollektivom organizatsii [Problems of the implementation of conflict-management in managing of work community of the organization]. Siberian Journal of economics and Management, 2019, Vol. 8, no. 1, pp. 7-24.

7. Kuntsman A.A. Spetsifika adaptatsii sovremennykh kompaniy k usloviyam tsifrovoy ekonomiki [The specificd of adapting modern companies to the conditions of digital economy]. Innovatsii [Innovations], 2017, no. $9(227)$, pp. 14-21. 
8. Makarova V.A. Formirovanie sistemy risk-menedzhmenta na predpriyatii [Formation of systemic risk management in the enterprise]. Vestnik Pskovskogo gosudarstvennogo universiteta. Seriya: Ekonomika. Pravo. Upravlenie [Herald of Pskov State University. Series: Economy. Law. Management.], 2014, no. 4, pp. 98-108.

9. Matveenko Yu.I. Sovremennye podkhody k izucheniyu riska [Modern approaches to risk study]. Izvestiya Tul'skogo gosudarstvennogo universiteta. Gumanitarnye nauki [Izvestia of Tula State University. Humanities], 2012, no. 1-1, pp. 165-173.

10. Savitskaya G.V. Ekonomicheskiy analiz: uchebnik 14-e izd., ispr. i dop. [Economic analysis: textbook]: M., INFRA-M, 2017. 649 p.

11. Agoraki M.-E.K., Delis M.D., Pasiouras F. Regulations, competition and bank risk-taking in transition countries. Journal of Financial Stability, 2011, no. 7(1), pp. 38-48.

12. Best practices in CCP Risk Management 2017. URL: https://www. lch.com/sites/default/files/media/files/Best\%20Practices\%20in\%20 CCP\%20Risk\%20Management_3.pdf?utm_source=Risk.Net\&utm medium $=$ Double $\% 20$ MPU\&utm_term $=$ CPM\&utm_content $=$ Risk $\% 20$ Whitepaper\&utm_campaign=Risk\%20Whitepaper, svobodnyy (data obrashcheniya: 18.07.2019).

13. Peter F. Elements of financial risk management. 2nd ed., 2012, pp. 291-326.

14. Thomas S., Carl P. Management: function and strategy. Annotated instructor's edition 2nd ed., Indiana University, 2002. 662 p.

15. Thomsen S., Pedersen T. Ownership structure and economic performance in the largest European companies. Strategic Management Journal, 2000, no. 21(6), pp. 689-705.

\section{ДАННЫЕ ОБ АВТОРАХ}

Бычкова Анна Андреевна, младший научный сотрудник Лаборатории моделирования пространственного развития территорий ФГБУН Институт экономики УрО РАН

ул. Московская, 29, г. Екатеринбург, 620014, Российская Федерация

annaby4kova@yandex.ru 
Никулина Наталья Леонидовна, кандидат экономических наук, старший научный сотрудник Лаборатории моделирования пространственного развития территорий ФГБУН Институт экономики УрО РАН ул. Московская, 29, г. Екатеринбург, 620014, Российская Федерация nikulinanl@mail.ru

\section{DATA ABOUT THE AUTHORS}

Bychkova Anna Andreevna, Associate Researcher, Laboratory for Spatial Territorial Development Modeling Institute of Economics of the Ural Branch of the Russian Academy of Sciences 29, Moskovskaya str., Yekaterinburg, 620014, Russian Federation annaby4kova@yandex.ru

SPIN-code: 4818-9384

ORCID: 0000-0001-8676-5298

Nikulina Natalia Leonidovna, $\mathrm{PhD}$ in Economics, Senior Researcher, Laboratory for Spatial Territorial Development Modeling Institute of Economics of the Ural Branch of the Russian Academy of Sciences 29, Moskovskaya str., Yekaterinburg, 620014, Russian Federation nikulinanl@mail.ru

SPIN-code: 1677-4125

ORCID: 0000-0002-6882-3172

ResearcherID: J-9846-2013

Scopus Author ID: 55960144700 